\title{
21st Century Schooling: Engaging Critical Need Teachers in Discourse on Classroom Management and Discipline
}

\author{
Marjorie Hall Haley \\ George Mason University, \\ Fairfax, USA
}

\author{
Sherry L. Steeley \\ Georgetown University, \\ Washington, D.C., USA
}

\author{
Sarah Eqab \\ George Mason University, \\ Fairfax, USA
}

\begin{abstract}
There is an increased demand for Arabic and Chinese language teachers across the country. The majority of these teachers are faced with the daunting realization that teaching in United States (U.S.) schools is tremendously different from their own schooling experiences. This study specifically focused on classroom management and discipline and examined how teachers address the challenges of working across languages and cultures of U.S. schooling. Research questions examined cross-cultural issues and classroom management, school culture and cultural differences, and teacher identity. Through a carefully designed sequence of blended learning activities, this study provided participants multiple opportunities to explore and examine introspectively critical considerations that directly influence transitioning to teaching in a learner-centered classroom utilizing various classroom management skills and strategies with millennial learners. Data collection instruments included two online surveys, a group interview, and online discussion board threads. Results indicate that critical need teachers face unique obstacles and challenges when transitioning into U.S. schools. Teachers actively addressed the process of reconciling the duality of their culture (and school culture) of origin with the U.S. classroom context, both in terms of incorporating their culture of origin and building upon it to address the needs of U.S. students.
\end{abstract}

Keywords: teacher beliefs and philosophy, cross-cultural understanding, foreign/second language teacher preparation

\section{Introduction}

Classroom management and discipline are two of the greatest challenges that new teachers face upon entering United States (U.S.) schools. While it is critically important that teacher candidates are highly competent in their respective disciplines, they are often completely unaware of precisely what is entailed in managing a classroom and effectively handling discipline. Most first-year teachers enter our classrooms excited and energetic, convinced that they are fully devoted to becoming outstanding, if not exemplary educators. They enter schools with high hopes and clear expectations of what teaching is and they are convinced that they will truly make a difference in the lives of their students. Then, it happens. They encounter the first disruptive student behavior or they find themselves teaching multiple levels of classes with a variety of culturally, cognitively, and linguistically diverse students. This may be further exacerbated by not having their own classroom, and therefore, must travel with a cart from one room to another (or several others).

Marjorie Hall Haley, Ph.D., professor, Graduate School of Education, George Mason University.

Sherry L. Steeley, Ph.D., instructional faculty, Center for Language Education and Development, Georgetown University.

Sarah Eqab, M.A., Ph.D. candidate, Graduate School of Education, George Mason University. 
Teacher training programs offer courses in classroom management, coupled with hours of field experience and a well designed and articulated student teaching internship. Teacher educators work tirelessly to simulate classroom situations and try to expose teacher candidates to the realities of teaching. However, it becomes glaringly apparent to new teachers that some lessons cannot be taught in such an artificial environment. In fact, most of good classroom management and discipline skills, strategies, and successes are results of "OJT" (on the job teaching). This situation is further compounded when we examine those teachers who are new to the culture of U.S. schooling. Specifically, teachers who were formally educated outside the U.S. and are training to become world language teachers in one of the 13 languages deemed "critical need" by the U.S. Department of State.

There is an increased demand for Chinese and Arabic language teachers across the country as those languages have been referred to by the U.S. federal government as critical need languages; languages that have been deemed critical to economic growth and national security. The majority of today's Arabic and Chinese teachers are faced with the daunting realization that teaching in U.S. schools is tremendously different from their own schooling experiences. To facilitate the transition for Chinese and Arabic language teachers to U.S. schools, the federal government has provided funding for various professional development programs. A study conducted on one such program is described in this paper: "Planning for Today's Learners: Effective Classroom Management and Discipline". Through a carefully designed sequence of blended learning activities, this summer program provided participants multiple opportunities to explore and examine introspectively critical considerations that directly influence transitioning to teaching in a learner-centered classroom utilizing various classroom management skills and strategies with millennial learners. Classroom management is one of the most prevalent reasons for job burnout and attrition of first-year teachers.

The summer program provided the attendees with three weeks of professional development workshops (10 in the summer and one in the fall) that focused on learner-centered instructional theories and methods and how to apply these theories and methods to actual teaching practices. During week one, teachers participated in a series of week-long tasks, readings, and online discussions. Week two included professional development workshops focused on learner-centered approaches to language teaching as highly effective tools for addressing pedagogical issues inherent in critical need languages. The participants conducted micro teaching simulations based on content information learned during week one. Week three was a continuation of online blended learning activities using the Ning as a social mediated platform.

When the teachers were not in classrooms, they participated in language specific online discussions facilitated by master teachers. During this time, the participants engaged in whole group discussions online and continued work on their final unit plan projects.

\section{Literature Review}

The large-scale, systematic study of classroom management was done by Kounin (1970). He analyzed videotapes of 49 1st and 2nd grade classrooms and coded the behavior of students and teachers. He identified several critical dimensions of effective classroom management. Those dimensions (among others) are: (a) "withitness"; (b) smoothness and momentum during lesson presentations; (c) letting students know what behavior is expected of them at any given point in time; and (d) variety and challenge in the seatwork assigned to students. In 1976, Brophy and Evertson reported the results of one of the major studies in classroom management, up to that point, in a book entitled Learning From Teaching: A Developmental Perspective. Their sample 
included some 30 elementary teachers whose students had exhibited consistently better than expected gains in academic achievement.

Four studies conducted at the Research and Development Center for Teacher Education in Austin, Texas, was a milestone in the research on classroom management. The first study involved 27 elementary school teachers. The second involved 51 junior high school teachers. Results from the elementary school study were reported in the study of Emmer, Evertson, and Anderson (1980). Results from the junior high study were reported in the studies of Evertson and Emmer (1982) and Sanford and Evertson (1981). Both studies were descriptive and correlational and they identified teacher actions associated with student on-task behavior and disruptive behavior. These studies supported Kounin's earlier findings. One of the more illustrative conclusions from these studies was that focusing on classroom management at the beginning of the school year is a critical component of a well-managed classroom.

The literature examining classroom management has primarily focused on the classroom system. According to Walker et al. (1996), "Classroom systems are developed by teachers to support the larger school-wide policies and procedures and to manage the academic performance and social behavior of students within instructional environments and arrangements" (p. 198). Studies concerning this context present proactive lesson-planning strategies for whole-class instruction and cooperative learning. In total, 17 studies were found for this review which highlight what researchers have found in this area. Five of these studies (Behets, 1997; Goolsby, 1996; Nelson, Johnson, \& Marchand-Martella, 1996; Stright \& Supplee, 2002; Vasquez-Levy, 1993) concern whole-class instruction, whereas four others (Christenson \& Serrao, 1997; Hannifin \& Clark, 1989 (as cited in Webb, Baxter, \& Thompson, 1997); Harwood, 1995; Hooper, Ward, Hannafin, \& Clark, 1989) present cooperative learning strategies. Looking at these earlier studies provided a pathway to substantiate the importance of the present study.

\section{Methods}

\section{Data Collection and Instruments}

Data were collected using three primary streams at designated points prior to, during, and after the summer program. The data collection instruments for this study included two online surveys (see Appendices A and D), a group interview protocol (see Appendix C), and online discussion board threads captured during week three on Ning (see Appendix B).

\section{Participants}

There were 19 participants involved in the study. The participants included a combination of both pre- and in- service Arabic and Chinese teachers. The in-service teachers were employed at both public and parochial K-12 schools. Teaching experience ranged from one to 17 years. Almost all participants held bachelor degrees in a non-language discipline. All participants were native or heritage speakers of either Arabic or Chinese. One participant was a U.S. born citizen. All others were from a Chinese- or Arabic- speaking country. The participants were all female. Their ages ranged from 23 to 51 . The participants all volunteered to participate in the research study.

In this next section, we outline procedures and research questions that guided the study.

\section{Procedures}

The study met all the requirements for Institutional Review Board (IRB). The participants were not paid 
any stipend and all willingly volunteered to take part in the research. Additionally, a brief overview of the research was provided in order that the participants fully understood what their involvement entailed.

Our formulated research questions were derived from our previous work with critical need language teachers. Based on those past experiences, we constructed the following questions.

\section{Research Questions}

Research question 1 (on cross-cultural issues and classroom management): How do Chinese and Arabic teachers negotiate the cross-cultural challenges inherent in classroom management?

Research question 2 (on school culture and cultural differences): How do culturally and linguistically diverse teachers/teachers of critical languages experience school culture?

Research question 3 (on teacher identity): How do teachers of critical languages perceive their identity as teachers?

\section{Data Analysis}

The Chinese and Arabic teacher participants engaged in pre- and post- surveys. Before the workshop, the participants were asked questions about their knowledge of classroom management philosophies and techniques. After the workshop, the participants completed the same survey. Pretest-posttest designs are often used in educational research primarily for comparing groups and/or measuring change (Dimitrov \& Rumrill, 2003). The results from the pre- and post- surveys of the participants in the StarTalk workshop were then analyzed to gain insight of any changes in the participants' responses after receiving direct instruction on classroom management and discipline. Nineteen participants completed the pre-institute survey; 15 completed the post-institute survey.

This analysis focuses on the pre- and post- survey results of the StarTalk Summer 2014 cohort. One of the first questions respondents reported on was about their knowledge of classroom management skills and strategies. In the pre-survey, the participants responded that 5.26\% had a high level of knowledge, $63.16 \%$ reported a medium level, and $31.58 \%$ reported a low level of knowledge. In the post-survey, the same question was responded to with very different results: $40 \%$ reported high levels of knowledge, $46.67 \%$ medium, and $13.33 \%$ low. A percentage increase of over $35 \%$ can be seen in the pre- and post- survey results in reference to the high level of knowledge participants felt after the workshop.

Several questions of the survey asked the participants to report to what degree they agreed or disagreed with a statement. The scale had the following rankings: "Strongly agree", "Agree", "Neutral", "Disagree", and "Strongly disagree". From the post-survey results, there were significant gains in the participants' knowledge of classroom management strategies. Table 1 illustrates the changes in the participants' awareness and understanding of these strategies and how they directly relate to student-teacher relationships, culture, and student input. One example of significant change in the participants' understanding of the role of student input in classroom management was observed in the following statement: "If students agree that a classroom rule is unfair, then I would replace it with one that students think is fair". In the pre-survey, $10.53 \%$ responded that they strongly agreed, $31.58 \%$ agreed, $26.32 \%$ were neutral, $21.05 \%$ disagreed, and $10.53 \%$ strongly disagreed. In the post-survey, $60 \%$ responded that they strongly agreed, $20 \%$ agreed, $13.33 \%$ responded neutral, $6.67 \%$ disagreed, and $0 \%$ strongly disagreed. Once again, the teachers' responses after the workshop suggest that teachers had changed their views on the importance of consensus of classroom rules and that creating them not only involved the teacher, but it also included the input of students in the classroom as well. Based on the 
results of the survey, we can see extensive learning in specific areas of classroom management directly relevant to student-teacher relationships, cultural expectations, and student motivation. Table 1 details these results.

Table 1

Survey Results on Student-Teacher Relationships, Cultural Expectations, and Student Motivation

\begin{tabular}{|c|c|c|c|c|}
\hline Question & & Pre-institute survey & Post-institute survey & Percentage change \\
\hline \multirow{3}{*}{$\begin{array}{l}\text { Describe your level of knowledge } \\
\text { about classroom management } \\
\text { skills and strategies. }\end{array}$} & High & $5.26 \%$ & $40.00 \%$ & $+34.74 \%$ \\
\hline & Medium & $63.16 \%$ & $46.67 \%$ & $-16.49 \%$ \\
\hline & Low & $31.58 \%$ & $13.33 \%$ & $-18.25 \%$ \\
\hline \multirow{5}{*}{$\begin{array}{l}\text { I believe that students need the } \\
\text { structure of a daily routine that is } \\
\text { organized and implemented by the } \\
\text { teacher. }\end{array}$} & Strongly agree & $63.16 \%$ & $86.67 \%$ & $+23.51 \%$ \\
\hline & Agree & $36.84 \%$ & $6.67 \%$ & $-30.17 \%$ \\
\hline & Neutral & $0.00 \%$ & $6.67 \%$ & $+6.67 \%$ \\
\hline & Disagree & $0.00 \%$ & $0.00 \%$ & $0.00 \%$ \\
\hline & Strongly disagree & $0.00 \%$ & $0.00 \%$ & $0.00 \%$ \\
\hline \multirow{5}{*}{$\begin{array}{l}\text { I believe that teachers should } \\
\text { direct the students' transitions } \\
\text { from one learning activity to } \\
\text { another. }\end{array}$} & Strongly agree & $52.63 \%$ & $46.67 \%$ & $+5.96 \%$ \\
\hline & Agree & $42.11 \%$ & $46.67 \%$ & $-4.56 \%$ \\
\hline & Neutral & $5.26 \%$ & $6.67 \%$ & $+1.41 \%$ \\
\hline & Disagree & $0.00 \%$ & $0.00 \%$ & $0.00 \%$ \\
\hline & Strongly disagree & $0.00 \%$ & $0.00 \%$ & $0.00 \%$ \\
\hline \multirow{5}{*}{$\begin{array}{l}\text { I believe that teachers should set } \\
\text { time for each learning activity and } \\
\text { try to stay within their lesson } \\
\text { plans. }\end{array}$} & Strongly agree & $57.89 \%$ & $73.33 \%$ & $+15.44 \%$ \\
\hline & Agree & $42.11 \%$ & $26.67 \%$ & $-15.44 \%$ \\
\hline & Neutral & $5.26 \%$ & $0.00 \%$ & $-5.26 \%$ \\
\hline & Disagree & $0.00 \%$ & $0.00 \%$ & $0.00 \%$ \\
\hline & Strongly disagree & $0.00 \%$ & $0.00 \%$ & $0.00 \%$ \\
\hline \multirow{5}{*}{$\begin{array}{l}\text { I believe that students need } \\
\text { direction from the teacher on how } \\
\text { to work together. }\end{array}$} & Strongly agree & $57.89 \%$ & $73.33 \%$ & $+15.44 \%$ \\
\hline & Agree & $26.32 \%$ & $20.00 \%$ & $-6.32 \%$ \\
\hline & Neutral & $15.79 \%$ & $6.67 \%$ & $-9.12 \%$ \\
\hline & Disagree & $5.26 \%$ & $0.00 \%$ & $-5.26 \%$ \\
\hline & Strongly disagree & $0.00 \%$ & $0.00 \%$ & $0.00 \%$ \\
\hline \multirow{5}{*}{$\begin{array}{l}\text { I believe that teachers should } \\
\text { allow students to select their own } \\
\text { seats. }\end{array}$} & Strongly agree & $5.26 \%$ & $0.00 \%$ & $-5.26 \%$ \\
\hline & Agree & $10.53 \%$ & $20.00 \%$ & $+9.47 \%$ \\
\hline & Neutral & $42.11 \%$ & $33.33 \%$ & $-8.78 \%$ \\
\hline & Disagree & $21.05 \%$ & $20.00 \%$ & $-1.05 \%$ \\
\hline & Strongly disagree & $21.05 \%$ & $33.33 \%$ & $+12.28 \%$ \\
\hline \multirow{5}{*}{$\begin{array}{l}\text { I believe that when students } \\
\text { behave appropriately, teachers } \\
\text { should provide a reward of some } \\
\text { kind such as points toward a party } \\
\text { or free time. }\end{array}$} & Strongly agree & $26.32 \%$ & $53.33 \%$ & $+27.01 \%$ \\
\hline & Agree & $57.89 \%$ & $46.67 \%$ & $-11.22 \%$ \\
\hline & Neutral & $10.53 \%$ & $0.00 \%$ & $-10.53 \%$ \\
\hline & Disagree & $5.26 \%$ & $0.00 \%$ & $-5.26 \%$ \\
\hline & Strongly disagree & $0.00 \%$ & $0.00 \%$ & $0.00 \%$ \\
\hline \multirow{5}{*}{$\begin{array}{l}\text { I believe that when a student } \\
\text { bothers other students, teachers } \\
\text { should immediately intervene to } \\
\text { stop the misbehavior. }\end{array}$} & Strongly agree & $52.63 \%$ & $60.00 \%$ & $+7.37 \%$ \\
\hline & Agree & $26.32 \%$ & $20.00 \%$ & $-6.32 \%$ \\
\hline & Neutral & $15.79 \%$ & $13.33 \%$ & $-2.46 \%$ \\
\hline & disagree & $10.53 \%$ & $6.67 \%$ & $-3.86 \%$ \\
\hline & strongly disagree & $0.00 \%$ & $0.00 \%$ & $0.00 \%$ \\
\hline \multirow{5}{*}{$\begin{array}{l}\text { If students agree that a classroom } \\
\text { rule is unfair, then I would replace } \\
\text { it with one that students think is } \\
\text { fair. }\end{array}$} & Strongly agree & $10.53 \%$ & $60.00 \%$ & $+49.47 \%$ \\
\hline & Agree & $31.58 \%$ & $20.00 \%$ & $-11.58 \%$ \\
\hline & Neutral & $26.32 \%$ & $13.33 \%$ & $-12.99 \%$ \\
\hline & Disagree & $21.05 \%$ & $6.67 \%$ & $-14.38 \%$ \\
\hline & Strongly disagree & $10.53 \%$ & $0.00 \%$ & $-10.53 \%$ \\
\hline
\end{tabular}




\section{Findings}

Further analyzing the process of these learning gains, we examined the participants' coursework related to the cultural issues involved in classroom management through their in-depth work with the online professional community participating in the summer program. Online work among the community of teachers focused on addressing classroom challenges, cultural differences, incorporating language and culture into a classroom management plan, and how to build on experiences and practices.

In order to address the research questions of this study, online work in the whole group and small group discussion area was downloaded, coded emically, for themes emerging from the data and etically, to respond directly to our questions.

\section{Overcoming Cultural Challenges}

One of the most explicit challenges for heritage language teachers, emphasized by both the Chinese and Arabic teachers, was the different role of the teacher in their cultures compared to the U.S. culture, and the impact on the student-teacher relationship. The participants also referenced more tightly regulated political systems, different learning and thinking skills, and different expectations for interactions between teachers and students and teachers and parents.

Other themes that emerged related to learning styles and thinking styles, the role of praise, interactions with parents, and the need to address cultural and economic diversity among students based on the school culture overall.

\section{Socio-political Context}

First, many participants saw a direct link between political philosophy and the classroom:

Influenced by Confucianism, Chinese students respect or even fear about their teachers. Most of the time in class, they sit quietly and obedient to teachers. However, the U.S. is a country values freedom and equality. American students can speak their own minds during class and the interaction between the teacher and the students is equal. Therefore, many Chinese teachers when they first teach American students, they might feel being offended. I think this is just cultural difference. Chinese teachers should know American students' characteristics before they officially teach in the U.S.. (Chinese teacher-1)

Some view this expectation of freedom negatively, as the outgrowth of a self-centered strand of American culture or freedom run amok:

Teachers had a lot of power in the school when I lived in Taiwan year ago. "You do what I said" was a norm at the time when I was a student. ...However, I found that students here have been giving too much of "I am the center of ... my voice should be heard ... you should not invade my space ...”, so much of me, me, me that as teachers we sometime not quite sure how to discipline the students here. A college friend of mine started her career as a college's professor year ago was stunted and frustrated by how her students were not respectful to teachers in the U.S.. (Chinese teacher-4)

\section{Student-Teacher Relationship}

The context referenced above directly impacted heritage language teacher views of the core classroom relationship: that between the students and their teacher. Overall, teachers' own educational experiences were marked by top-down, teacher-centered classroom management structures, a high degree of respect among students for their teachers, and a directive teaching style. Many noted the very different expectations among each group, with American students expecting a role in creating the rules vs. a top-down, teacher-centered approach to classroom procedures and discipline. 
When it comes to the difference between American students and Arabic students in terms of their classroom management, we can say that we are in front of two different "systems" because it is not about context, yet it is about the relationship teacher/student that draws the whole atmosphere in the classroom, it means that an Arabic student has to follow the classroom rules without any objection, so there is no way to let him/her participate in creating the rules. Moreover, punishment, even physical punishment using the ruler to hit students' hands, is often common in Arabic classroom. It is a part of classroom management. (Arabic teacher-5)

\section{Learning Styles}

What many of the teachers refer to as learning styles actually seems to be cultural preferences that impact upon classroom organization. Several mentioned the need for greater interaction in American classrooms:

American classrooms focus on various kinds of learning style students. Students will work in groups, discuss with each other, and figure out the problem by cooperation. (Arabic teacher-1)

I think American students are more open, more extraversion, so we need use reinforced and emphasized rules; Chinese students are more quiet and more introversion, so we need give them more encouragement for expressing, talking, and communicating. (Chinese teacher-9)

\section{Thinking Styles}

Several teachers observed that they had taken their own pattern of thinking for granted, realizing over the course of their collaboration that they needed to be very concrete and specific in approaching their students:

I think that the kids know the rules already, although I did not spend time describing the rules to them. They should learn and keep in mind. When the kids are driving me crazy by asking me you did not tell us before, why should you ask me to do that! Somehow I can say, before attending this workshop, I even did not plan to set up routine to my classes. As a first-year teacher, it is really worth to join you guys this summer. (Chinese teachers-6)

Another surprise for many participants in terms of its impact on classroom management was the realization of what they termed the American style of critical thinking, and the challenges it poses to them as teachers.

In terms of classroom management, the participants noted that they needed not only rules and routines, but also an overall framework and rationale:

I think American students would question the teacher about the purpose of a certain rule while Arabic students will not, most of the times. (Arabic teacher-2)

In terms of teaching challenges, the questioning forces the teachers to think more deeply:

It happens a lot that American students would question more during the lesson. Especially when we talk about culture, they always want to know more and why. I like their critical thinking and I think we should encourage more critical thinking in our classroom by giving them open-ended questions. (Chinese teacher-7)

\section{Praise}

Interestingly, one area in which teachers had noticed significant differences between their home cultures and that of U.S. schools is in the role of praise. Some felt negatively about this, that there is too much praise:

I also feel that the teachers do more praising in the American classroom and the students expect the praise more than the Chinese students. I read an article raising the question "Whether the American students are receiving too much praise". I wonder about that as well. (Chinese teacher-10)

Chinese students learn from the criticism from their teachers and parents. The students are used to strict rules and difficult exams, so when they are frustrated, they see it is normal and get back on their feet right away. American students learn well when their teachers and parents praise them. However, when they get frustrated, they give up easily. I always have to find a way, such as to tell them "Come on! You can do it. Let us just try one more time". (Chinese teacher-3) 


\section{Interactions With Parents}

Many of the teachers expressed challenges in communicating with both American parents and heritage language parents, but expressed a desire to overcome the difficulties to work with them effectively:

Communicating with parents is not easy! I heard many Chinese teachers complain about this. I think your solution that explaining our Chinese classroom culture to parents is very important. Parents should know that this is just our culture instead of thinking we are not high-quality teachers. We should keep an open communication with our students' parents, after all, we have the same goal—-promote students' learning. (Chinese teacher-2)

\section{Overall Impact}

Many participants noted the internal, psychological impact of their first cultures on their approach to students, and challenges they face as a result:

... Chinese culture also makes me sometimes overcautious and think too much. I am not confident enough to hold a class and I focus too much on how will the students think about me. It always comes to my mind "Am I teaching in a good way?", "My students are laughing, are they laughing at me?", and "Did I say something wrong?". But meanwhile, I want my class to be well organized. (Chinese teacher-5)

This view reflected that many participants experienced a lack of confidence in understanding how to approach classrooms in the U.S. context, based on the differential expectations of U.S. schools, students, and parents.

\section{Developing a Cross-Cultural Classroom Management Plan}

In approaching a classroom management plan, teachers used ideas from their culture of origin and teaching the target language along with new ideas related to student-centeredness, engagement, and constructing a classroom community.

\section{Incorporating Culture of Origin Into the U.S. Classroom}

Several participants focused first on the respect accorded to teachers, but viewed that critically, noting that respect had to be mutually constructed, and that the teacher should work for that respect:

In my culture, the respect and value for the teacher is very important. A teacher holds a very high role in the classroom, like a master. I remember the old saying "Who teaches me a letter I will become his slave" (حرفـا علمـني من (عبـدا لـ كنــ. While respect is very important to the teacher, I believe that we should also respect the students and treat them as a whole. This leads to a good relationship between both. (Arabic teacher-3)

In order to address these issues, the participants reiterated across the domains of learning styles, student diversity, and cultural differences that they were committed to creating an atmosphere through an engaged and inclusive classroom community.

\section{Using First Language}

Many teachers expressed the difficulty in using the target language, particularly for procedural and classroom management purposes.

Using only the target language, some students might shut down if they fall behind and cannot catch up with the class as a whole. (Arabic teacher-6)

Nevertheless, they also expressed a commitment to finding ways to develop ideas for doing so:

Students often use direct translation when trying to understand the target language, which can be inefficient. Since 
directly translating words or phrases to another language does not always result in the correct translation, students can be misled, and they may have a misunderstanding with the teacher, who knows the target language at a deeper level. Therefore, it is important for the teacher to look at everything from the student's perspective while managing the classroom in order to avoid unnecessary misunderstandings. (Arabic teacher-4)

\section{Student Centeredness}

Diversity. One area that was a prevalent concern for the participants was addressing the diversity in their classrooms in fair and responsive ways.

Most of the Chinese students, no matter here or in the U.S., have similar background. Traditional beliefs can influence them more or less. However, it will be hard for teachers to have just one way/method to teach American students who comes from all over the world. (Chinese teacher-8)

This was a new experience for many and there was extensive discussion of how to approach this:

In our culture, there is no planning for students of different levels, no routine, no activities, no relationship, no working as a group, etc.. I find that this is very sad and I have changed my teaching ways so that the students receive a fun learning experience and they leave school feeling happy and encouraged to come back the next day. (Chinese teacher-11)

I think the heterogeneous student population in American schools will be a difficult problem for me when I become a teacher. I might be confused what kind of rules are acceptable for all students. For example, eye contact is very common in American culture, however, some Asian students might feel not comfortable about this. (Chinese teacher-13)

Classroom community. Creating classroom community seemed to focus on two aspects: respect for students and incorporation of a variety of perspectives.

I think the biggest difference between Chinese culture and here is the value towards people. We tend to focus on conformity and obedience in appearance, in order to achieve that, we always take the short cut sometimes including harsh criticism and discipline. The focus is on result not on people. But here, all students are respected and their needs are being addressed individually. The focus is on students as individual, result is the byproduct of good relationship and inspiration. It takes longer to achieve the result, but it also lasts longer and a much happier experience for students. (Chinese teacher-12)

Creating the classroom rules and the consequences should be team work allowing all the students to create the list together so, it will include all cultures. (Arabic teacher-5)

Even though it is difficult for teachers to take care of every student's feeling, it is still important for us, as educators, to know more about our students and let them know we value their own culture and we really care about them. (Arabic teacher-1)

\section{Discussion}

Based on the "processing" elements of heritage language teachers' transition to U.S. schools, the data based on group discussion indicate significant areas of growth. One critical was that teachers actively addressed the process of reconciling the duality of their culture (and school culture) of origin with the U.S. classroom context, both in terms of incorporating their culture of origin and building upon it to address the needs of U.S. students. This is significant because it emphasizes an "additive" view of cultural origin, rather than a "subtractive" view that would indicate abandonment and rejection of first culture. Nevertheless, this is a daunting process, indicating the need for ongoing support through active communities of learning to provide support as teachers continue to develop their planning, classroom approaches, cultural transitions, and growth process.

Perhaps of equal significance is the insightful discussion of both "macro level" issues, such as socio-political factors - which have both positive and negative mitigating influence, according to teacher 
discussion - as well as "micro level" factors, such as learning and communication styles that arise in the classroom. This level of perspective is extraordinary, because it encompasses a fuller view of school (and systemic) philosophy and creates the foundation for school approaches that are firmly grounded in both culture of origin and U.S. culture.

Survey results demonstrated that this "process approach" to classroom management had very positive results. It is logical to conclude that development in this area will be more sustainable, because it is broadly based, and that teachers drew strength, insight, and personal and professional development benefits from both training and the support of a professional community of peer heritage language teachers.

\section{Conclusion}

This study was an investigation of the impact of one U.S. StarTalk program. It was an attempt to further measure and substantiate worthiness and impact, relative to classroom management. This program was specifically constructed for Arabic and Chinese pre- and in- service teachers. In the study, we focused on the critical topic of classroom management and discipline. This issue in U.S. education is difficult to master for those teachers born and trained here. It is further exacerbated for critical need language teachers who come with different educational/schooling backgrounds.

"In the U.S., we lose about half our teachers in the first five years", said Mike Anderson, a responsive classroom consultant for Northeast Foundation for Children Inc., in his 2012 Annual Conference session, Classroom Management for New Teachers (Anderson, 2012). "What's particularly startling is that it takes about five years for teachers to get their feet under them". The teachers in our study noted that they were primarily concerned about not being able to control their classes mostly because they were unaware of the cultural nuances embedded in the culture of U.S. schooling. However, the teacher participants in the study were not discouraged of dissuaded as they grappled with the many challenges of transitioning into the culture of U.S. schooling. They were vibrant and active members of the learning community created in both the face-to-face segment of the summer program and also the online discussions that followed.

In order to enhance this type of learning community, a key factor would be providing the ongoing professional support described above; such professional communities can support cultural adjustments, ongoing problem solving, and the larger dilemmas presented by reconciling very disparate cultural frameworks in the context of the U.S. classroom. The results of this study draw attention to some of the challenges and complexities faced by critical need language teachers.

We are pleased with the results of this study. It provides substantive support of the continuation of StarTalk programs. Further, this study contributes to the dearth of existing research on the professional development of teachers of critical need languages. We acknowledge that this work illustrates the need for further research and we hope that this will serve as a catalyst to encourage other researchers to undertake a similar research agenda.

\section{References}

Anderson, M. (2012). Responsive classroom schools conference. Retrieved January 12, 2015, from http://www.zoominfo.com/p/ Mike-Anderson/181398813

Behets, D. (1997). Comparison of more and less effective teaching behaviors in secondary physical education. Teaching and Teacher Education, 13(2), 215-224.

Brophy, J., \& Evertson, C. (1976). Learning from teaching: A developmental perspective. Boston, M.A.: Allyn \& Bacon. 
Christenson, M., \& Serrao, S. (1997). Cooperative learning in a hostile environment. Teaching and Change, 4(2), 137-156.

Dimitrov, D., \& Rumrill, P. (2003). Pretest-posttest designs and measurement of change. Work, 20(2), 159-165.

Emmer, E., Evertson, C., \& Anderson, L. (1980). Effective classroom management at the beginning of the school year. The Elementary School Journal, 80, 219-231.

Evertson, C., \& Emmer, E. (1982). Effective classroom management at the beginning of the school year in junior high classes. Journal of Educational Psychology, 74, 485-498.

Goolsby, T. (1996). Time use in instrumental rehearsals: A comparison of experienced, novice, and student teachers. Journal of Research in Music Education, 44(4), 286-303.

Harwood, D. (1995). The pedagogy of the world studies 8-13 project: The influence of the presence/absence of the teacher upon primary children's collaborative group work. British Educational Research Association, 21(5), 587-611.

Hooper, S., Ward, T., Hannafin, M., \& Clark, H. (1989). The effects of aptitude composition on achievement during small group learning. Journal of Computer-based Instruction, 16, 102-109.

Kounin, J. S. (1970). Discipline and group management in classrooms. New York, N.Y.: Holt, Rinehart \& Winston.

McManus, S., \& Gettinger, M. (1996). Teacher and student evaluations of cooperative learning and observed interactive behaviors. The Journal of Educational Research, 90(1), 13-22.

Nelson, J., Johnson, A., \& Marchand-Martella, N. (1996). Effects of direct instruction, cooperative learning, and independent learning practices on the classroom behavior of students with behavioral disorders: A comparative analysis. Journal of Emotional and Behavioral Disorders, 4(1), 53-62.

Sanford, J., \& Evertson, C. (1981). Classroom management in a low socioeconomic status junior high: Three case studies. Journal of Teacher Education, 32, 34-38.

Stright, A., \& Supplee, L. (2002). Children's self-regulatory behaviors during teacher-directed, seat-work, and small-group instructional contexts. The Journal of Educational Research, 95(4), 235-246. Retrieved from http://infotrac.galegroup.com

Vasquez-Levy, D. (1993). The use of practical arguments in clarifying and changing practical reasoning and classroom practices: Two cases. Journal of Curriculum Studies, 25(2), 125-143.

Walker, H., Horner, R., Sugai, G., Bullis, M., Sprague, J., Bricker, D., \& Kaufman, M. (1996). Integrated approaches to preventing antisocial behavior patterns among school-age children and youth. Journal of Emotional and Behavioral Disorders, 4(4), 194-209.

Webb, N., Baxter, G., \& Thompson, L. (1997). Teachers' grouping practices in fifth-grade science classrooms. The Elementary School Journal, 98(2), 91-113.

\section{Appendix A: GMU StarTalk 2014—Pre-survey}

(Pre-survey link: https://www.surveymonkey.com/s/STSQ9C2)

1. What is your name?

2. Do you currently hold a teaching license?

3. Are you currently employed as a language teacher?

4. What language(s) do you teach or will you teach?

5. What do you hope to gain from this StarTalk summer institute?

6. Why are daily routines important in classroom management?

7. What are some examples of daily routines?

8. How can teachers help students smoothly transition from one activity to another activity?

9. How can teachers establish rules in their classroom?

10. What are some ways teachers manage time and stay within their lesson plan for each learning activity?

11. Should teachers allow students to select their own seats? Why?

12. How can teachers reward students who behave appropriately?

13. How should teachers deal with a student who misbehaves in the classroom?

14. What are some ways to deal with a defiant student?

15. How can teachers adjust their lesson for the students with individual learning needs? 
16. Should the students be allowed to freely use any materials in the classroom during the learning process? Why? Why not?

17. Should the students be allowed to direct themselves (self-pace and directed) during classroom activities? Why? Why not?

18. Is it important to continuously monitor students during seatwork? Why? Why not?

19. How can teachers deal with students who do not turn in homework routinely?

20. Describe your level of knowledge about classroom management: High__ Medium Low

21. I believe students need the structure of a daily routine that is organized and implemented by the teacher. $\begin{array}{llllllll}2 & 2 & 3 & 5\end{array}$

22. I believe teachers should direct the students' transitions from one learning activity to another. $\quad \begin{array}{lllll}1 & 2 & 3 & 4 & 5\end{array}$

23. I believe teachers should set time for each learning activity and try to stay within their lesson plans. $\begin{array}{llllll}1 & 2 & 3 & 4 & 5\end{array}$

24. I believe that students need direction from the teacher on how to work together.

$\begin{array}{lllll}1 & 2 & 3 & 4 & 5\end{array}$

25. Teachers should allow students to select their own seats.

26. When students behave appropriately, teachers should provide a reward of some kind such as points toward a party or free time.

27. When a student bothers other students, teachers should immediately intervene to stop the misbehavior. $1122 \quad 3 \quad 4 \quad 5$

28. If students agree that a classroom rule is unfair, then I would replace it with one that students think is fair. $\begin{array}{llllllll}1 & 2 & 3 & 4 & 5\end{array}$

\section{Appendix B: Online Ning Questions: World Readiness Standards for Language Learning}

\section{Day 1: Cross-Cultural Aspects of Classroom Management}

\section{Whole group questions:}

During week 1, we discussed the various aspects of classroom management, including cultural aspects and appropriacy.

How does your own culture impact your classroom management plan?

What are your challenges in this area?

\section{Small group questions:}

1. What are some of the differences between American and Chinese or Arabic students in terms of their classroom management needs?

2. Please select one facet of classroom management to explore more deeply (grading policy, seating arrangement, movement and activities, reward and discipline system, etc.) to address these questions.

\section{Day 2: Classroom Community, Responsive Classrooms, and Discipline}

\section{Whole group questions:}

1. What are some ways that you have created a classroom community among your students?

2. How would you like to incorporate principles of a responsive classroom?

3. What kind of discipline plan do you have in place?

\section{Small group questions:}

1. What are some cultural issues involved in classroom community?

2. How does a responsive classroom complement or conflict with your ideas about classroom management?

3. How does the target language impact a classroom community, for good and for bad?

\section{Day 3: Classroom Management and Target Language Instruction}

\section{Whole group questions:}

1. How does your target language impact your overall approach to classroom management?

2. How do standards relate to your classroom management plan?

3. How do the 5 Cs inform the process? 


\section{Small group questions:}

1. What cultural challenges do you face in using the target language for classroom management?

2. What linguistic issues do you face?

3. How will these impact your classroom management plan?

\section{Day 4: Classroom Management and Technology}

\section{Whole group questions:}

1. Based on your discussion during week 1 and Lori Roe's presentation, what aspects of technology can you incorporate to your current approach to classroom management? How will you incorporate them?

2. What aspects of technology would you like to explore for designing an updated classroom management plan? Why?

\section{Small group questions:}

1. What are the benefits of technology for classroom management?

2. What are some of the barriers to using technology?

3. What cultural or language issues arise in using technology for classroom management purposes?

\section{Appendix C: Post Simulation Teaching Group Interview Questions}

1. Let us begin by introducing ourselves. Please tell us your name.

2. Could you share with us how you planned and designed your activities for your lesson today? For example:

a. What was the objective of your lesson?

b. Was it based on the standard and if "Yes", which one?

c. If not, how did you develop your objective?

d. Do you think you were able to incorporate classroom management skills? How?

3. What worked well during your instruction? Why do you think/feel it worked well?

4. What did not work so well during your instruction? Why do you think/feel it didnot work so well?

5. What would you do differently the next time you try these kinds of activities?

6 . How could you tell if the students comprehended what you were teaching?

7. What did you learn about yourself as a teacher?

8. Is there anything else you would like to say about teaching the students in the language camps?

\section{Appendix D: GMU Startalk 2014—Post-survey}

(Post-survey link: https://www.surveymonkey.com/s/QGZW5P7)

1. What is your name?

2. Do you currently hold a teaching license?

3. Are you currently employed as a language teacher?

4. What language(s) do you teach or will you teach?

5. What did you learn from this StarTalk summer institute?

7. Why are daily routines important in classroom management?

8. What are some examples of daily routines?

9. How can teachers help students smoothly transition from one activity to another activity?

10. How can teachers establish rules in their classroom?

11. What are some ways teachers manage time and stay within their lesson plan for each learning activity?

12. Should teachers allow students to select their own seats? Why? 
13. How can teachers reward students who behave appropriately?

14. How should teachers deal with a student who misbehaves in the classroom?

15. What are some ways to deal with a defiant student?

16. How can teachers adjust their lesson for the students with individual learning needs?

17. Should the students be allowed to freely use any materials in the classroom during the learning process? Why? Why not?

18. Should the students be allowed to direct themselves (self-pace and directed) during classroom activities? Why? Why not?

19. Is it important to continuously monitor students during seatwork? Why? Why not?

20. How can teachers deal with students who do not turn in homework routinely?

21. Describe your level of knowledge about classroom management: High Medium Low

22. I believe students need the structure of a daily routine that is organized and implemented by the teacher. $\begin{array}{llllll}1 & 2 & 3 & 4 & 5\end{array}$

23. I believe teachers should direct the students' transitions from one learning activity to another.

$\begin{array}{lllll}1 & 2 & 3 & 4 & 5\end{array}$

24. I believe teachers should set time for each learning activity and try to stay within their lesson plans.

$\begin{array}{lllll}1 & 2 & 3 & 4 & 5\end{array}$

25. I believe that students need direction from the teacher on how to work together.

$\begin{array}{lllll}1 & 2 & 3 & 4 & 5\end{array}$

26. Teachers should allow students to select their own seats.

27. When students behave appropriately, teachers should provide a reward of some kind such as points toward a party or free time.

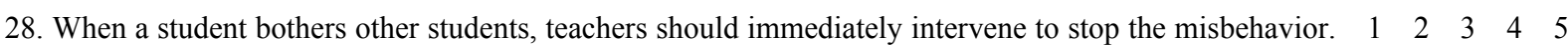

29. If students agree that a classroom rule is unfair, then I would replace it with one that students think is fair. $1 \quad 2 \quad 3 \quad 4 \quad 5$ 